\title{
PROF. DR. OSMAN MERT VE KÖLİ ÇOR YAZITI VE ANIT MEZAR KOMPLEKSİ ADLI ESERİ ÜZERİNE
}

İsmail ÇOBAN*

\section{Prof. Dr. Osman MERT'in Öz Geçmişi ${ }^{1}$ :}

1971 yılında Mersin'in Erdemli ilçesinde dünyaya gelen Osman MERT, ilk ve orta öğrenimini Erdemli'de tamamlar. 1994 yılında Atatürk Üniversitesi Kâzım Karabekir Eğitim Fakültesi Türk Dili ve Edebiyatı Eğitimi Bölümünden mezun olur. Aynı yıl Atatürk Üniversitesi Kâzım Karabekir Eğitim Fakültesi Türk Dili ve Edebiyatı Eğitimi Bölümünde "Araştırma Görevlisi” olarak göreve başlayan MERT, 1996 y1lında “Hamdullah Subhi Tanrı̈̈ver'in 'Dağyolu II' Adlı Eserinde Söz Dizimi” adlı yüksek lisans çalışmasını tamamlayarak “Türk Dili Uzmanı" olur.

MERT, 1996 yılında başladığı doktora öğrenimini Prof. Dr. Dr. Cengiz ALYILMAZ yönetiminde hazırladığı “Kutadgu Bilig'de Hâl Kategorisi” adlı doktora çalışması ile 2002 yılında tamamlayarak "Türk Dili Doktoru” unvanını alır.

Gürcistan Cumhuriyeti'nde Yaşayan Türkler'in Dünü ve Bugünü (Eğitim, Dil, Edebiyat, Tarih, Etnoloji ve Yüzey Araştırmaları); Türk Kültüründe Yazı Kavramının Gelişimi; Güney Türkistan, Kafkaslar ve Avrupa'daki Türk Yazıtları ve Turfan ve Komşu Bölgelerdeki Runik Yazıtlarla İlgili Epigrafik ve Fotogrametrik Araştırmalar; “Türk Dünyası Vatandaşlığı” Ders Programı Geliştirilmesi ve Etkililiğinin Değerlendirilmesi; Nahçıvan -Erzurum İpek Yolu Güzergâhındaki Türk Kültür ve Uygarlık Eserlerinin Araştırılması; Çin Halk Cumhuriyeti, Orta Asya Türk Cumhuriyetleri ve Rusya Federasyonu'ndaki Yazıtlarla İlgili Epigrafik ve Fotogrametrik Araştırmalar adlı projelerde araştırmacı olarak görev alır.

2002 - 2004 yılları arasında Atatürk Üniversitesi Kâzım Karabekir Eğitim Fakültesi Türkçe Eğitimi Bölümü Bölüm Başkan Yardımcılığı görevini yürüten MERT, 2007 - 2008 öğretim yılında Moğolistan Millî Üniversitesi Yabancı Diller ve Kültürler Fakültesi Türkoloji Bölümünde misafir öğretim üyesi olarak çalışır. Moğolistan'da bulunduğu bu dönemde Moğolistan Millî Üniversitesi Yabancı Diller ve Kültürler Fakültesinde Moğolca Hazırlık Programı'nı tamamlar.

\footnotetext{
* Arş. Gör.; Atatürk Üniversitesi Kâzım Karabekir Eğitim Fakültesi Türkçe Eğitimi Bölümü, smlcoban@ gmail.com.

${ }^{1}$ Bu bölüm, yazarın Köli Çor Yazıtı ve Anıt Mezar Kompleksi adlı eserinden hareketle oluşturulmuştur.
} 
05.01.2011 tarihinde “Türk Dili” alanında Doçent unvanını alır.

MERT, 2012 yılında Atatürk Üniversitesi Dil Eğitimi Uygulama ve Araştırma Merkezi; Orta Doğu ve Orta Asya - Kafkaslar Araştırma ve Uygulama Merkezi Müdürlüklerine ve Türkiyat Araştırmaları Enstitüsü Müdür Yardımcılığına atanır.

2013 y1lında Türk Keneşi (Konseyi) Türk Üniversiteler Birliği Yüksek Öğretim Alanı Oluşturma Yönergesi Hazırlama Komisyonunda görev alan Osman MERT, aynı yıl Atatürk Üniversitesi Türk Dili Dersleri Koordinatörlüğ̈̈ne; 2014 yılında ise Atatürk Üniversitesi Süreli Yayınlar Koordinatörlüğüne atanır.

2012 yılından bu yana Atatürk Üniversitesi Türkiyat Araştırmaları Enstitüsü Dergisi’nin Editörlüğünü yürüten Osman MERT, aynı zamanda Uluslararası TEKE (Türkçe Edebiyat Kültür Eğitim) Dergisi’nin Editör Yardımcıllı̆ı görevini de sürdürmektedir.

MERT, 2016 yılında “Türk Dili” alanında Profesör unvanını alır.

Kâzım Karabekir Eğitim Fakültesi Türkçe Eğitimi Bölümünde öğretim üyesi olarak görev yapan Osman MERT, hâlen idari görevlerinin yanında Orta Asya'da, Orta Doğu'da, Balkanlar'da ve Kafkaslar'da Türklük Bilimi ile ilgili çalışmalarını sürdürmektedir.

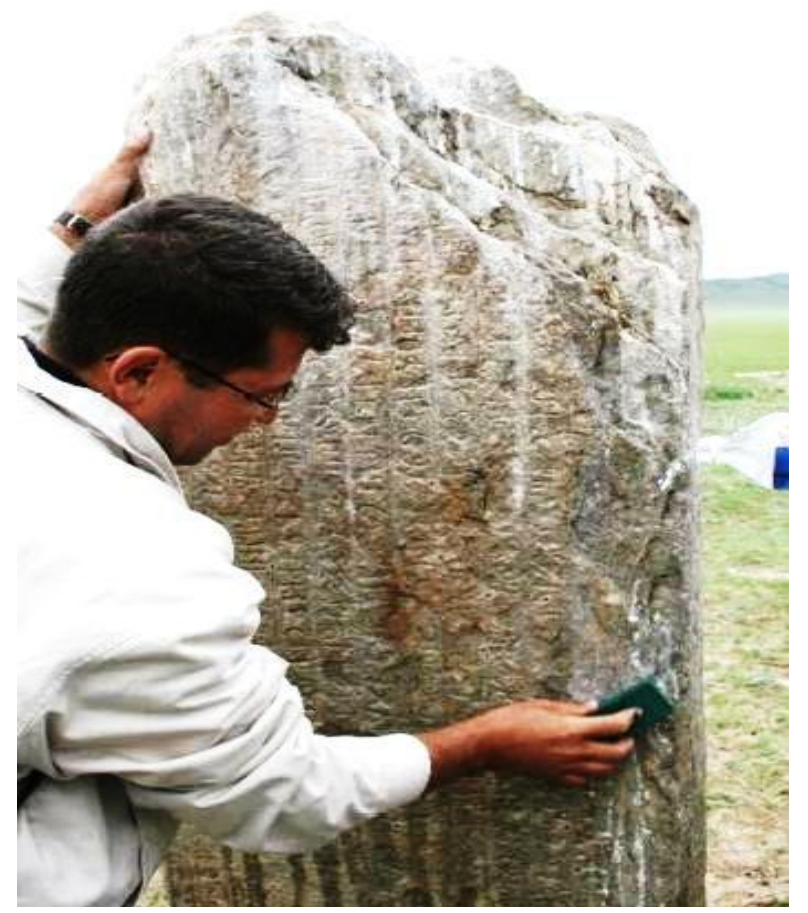

Foto 1: Prof. Dr. Osman MERT, Köli Çor Yazıtı'nı estampaj için hazırlarken (Foto: Cengiz ALYILMAZ) 


\section{Prof. Dr. Osman MERT'in Yayınları:}

\section{- Makaleleri:}

Mert, O. (1999). Türkçe Sözlük'ün Ters Dizimi Üzerine. Atatürk Üniversitesi Türkiyat Araştırmaları Enstitüsü Dergisi, 11, 311-316.

Mert, O. (2001). Azerbaycanlı Şair, Yazar Veli Hramçaylı. Atatürk Üniversitesi Türkiyat Araştırmaları Enstitüsü Dergisi, 18, 179-186.

Mert, O. (2001). Osman F. SERTKAYA - Cengiz ALYILMAZ - Tsendiyn BATTULGA, Moğolistan'daki Türk Anttları Projesi Albümü / Album of The Turkish Monuments In Mongolia), (Türk İşbirliği ve Kalkınma İdaresi Başkanlığı (TIKKA) Yayınları, Ankara, 2001, XXXIII+354. Türk Dili, 607, 313-315.

Mert, O. (2002). Türkçe Eğitimi ve Öğretimi Üzerine Bir Bibliyografya Denemesi. Atatürk Üniversitesi Türkiyat Araştırmaları Enstitüsü Dergisi, 19, 349-381.

Mert, O. (2003). Oktay BELLİ, Kırgızistan'da Taş Balbal ve İnsan Biçimli Heykeller Stone Balbals and Statues in Human Form in Kirghizistan. Arkeoloji ve Sanat Yayınları, İstanbul, 2003, VIII+166 s. Atatürk Üniversitesi Türkiyat Araştırmalarn Enstitüsü Dergisi, 22, 327-329.

Mert, O. (2003). Türkçe'de Hâl Kategorisi ve Öğretimi. Atatürk Üniversitesi Türkiyat Araştırmaları Enstitüsü Dergisi, 21, 25-32.

Mert, O. (2004). Gürcistan (Borçalı) Karapapaklarının/ Terekemelerinin Eğitim Tarihine Dair. Atatürk Üniversitesi Türkiyat Araştırmaları Enstitüsü Dergisi, 24, 233-252.

Mert, O. (2006). İsmail Doğan, Atilla'nın Torunları Sekeller. Yeni Avrasya Yayınları, Ankara, 2005, 147 s. Karadeniz Araştırmaları, 8, 147-148.

Mert, O. (2007). Kemaliye'de Eski Türk İzleri: Dilli Vadisindeki Petroglif ve Damgalar. Atatürk Üniversitesi Türkiyat Araştırmaları Enstitüsü Dergisi, 34, 233-254.

Mert, O. (2008). Orhun Yazıtlarında Kullanılan İşaretsiz (/.ø./) Görev Ögeleri. Atatürk Üniversitesi Türkiyat Araştırmaları Enstitüsü Dergisi, 38, 1-20.

Mert, O. (2008). Öngöt Mezar Külliyesi ve Külliyede Bulunan Damgalar. Atatürk Üniversitesi Türkiyat Araştırmaları Enstitüsü Dergisi, 36, 281-306.

Mert, O. (2009). Şaahar Tepesi ve Bölgede Bulunan Kaya Üstü Tasvir, Damga, Yazıt ve Kurganlar. Atatürk Üniversitesi Türkiyat Araştırmaları Enstitüsü Dergisi, 40, 1-24. 
Mert, O., Alyılmaz, S., Bay, E. ve Akbaba, S. (2009). Orhun Yazıtlarındaki Toplumsal Değerlerin Öğretmen Adayları Tarafından Algılanma Düzeyi Üzerine Bir Araştırma. The Journal of International Social Research, 2(9), 279-287.

Bay, E., Mert, O. ve Ozan, C. (2011). İlköğretim 6-8. Sınıflarda Ortaya Çıkan İstenmeyen Öğrenci Davranışları ve Öğretmenlerin Davranış Yönetim Stratejileri. Kâzım Karabekir Eğitim Fakültesi Dergisi, 23, 49-70.

Bay, E., Mert, O., Alyılmaz, S. ve Albayrak, F. (2012). Eski Türk Eserlerine İlişkin Tutum Ölçeği Geliştirilmesi. Uluslararası Türkçe Edebiyat Kültür Eğitim Dergisi, 1(2), 70-82.

Mert, O. (2013). Köl Tigin ve Bilge Kağan Yazıtlarında Boşluk Karakterinin (/ : /ø/ •/) Kullanımıyla İlgili Karşılaşılan Farklılıklar. Yalım Kaya Bitigi. Osman Fikri Sertkaya Armă̆anı, Ankara, 1-30.

Mert, O. (2013). Prof. Dr. Osman Fikri Sertkaya ve "Makaleler -2 (Seçme Araştırma ve İncelemeler) Adlı Eseri Üzerine. Uluslararası Türkçe Edebiyat Kültür Eğitim Dergisi, 2(4), 366-403.

Mert, O. ve Albayrak F. (2013). Köl Tigin ve Bilge Kağan Yazıtlarının Metinlerinde Ünlülerin Yazımıyla İlgili Karşılaşılan Farklılıklar. Uluslararası Türkçe Edebiyat Kültür Eğitim Dergisi, 2(2), 86-115.

Mert, O., Albayrak, F. ve Serin, N. (2013). Çeviri Çocuk Kitaplarının Kültür Aktarımı Açısından İncelenmesi. Ana Dili Ĕ̈itimi Dergisi, 1(3), 58-73.

Mert, O., Gündoğdu, K. ve Albayrak, F. (2013). An Investigation of Foreign Turkic Orginated Students' Difficulties in Learning Writting Skills in Turkic Language. International Journal of Humanities and Social Science 3(2), 130-141.

Mert, O. (2015). Karakurum Bölgesi'ndeki Arap Harfli Yazttlar. Atatürk Üniversitesi Türkiyat Araştırmaları Enstitüsü Dergisi, 54, 1-29.

Mert, O. (2015). Türk Konseyi (Keneşi) Türk Üniversiteler Birliği ve Türk Üniversiteler Birliği I. Genel Kurulu. Atatürk Üniversitesi Türkiyat Araştırmaları Enstitüsü Dergisi, 53, 273290.

Mert, O. ve Bozkırlı, K. (2015). Orhun Yazıtları'nda Boyları Bir Araya Getirme Çabaları. Uluslararası Türkçe Edebiyat Kültür Eğitim Dergisi, 4/1, 1-15.

Bay, E., Demir, S., Mert, O. vd. (2015). Kültürler Arası Eğitim Bağlamında Türk Dünyas1 Vatandaşlı̆̆ı Ders Programı Geliştirilmesi Projesi. Uluslararası Türkçe Edebiyat Kültür Ĕ̈itim Dergisi, 4(1), 86-97. 


\section{- Bidirileri:}

Mert, O. (2007). Kazak Türkçesinde Hayvan Adlarıyla Kurulmuş Atasözleri. Kazakistan ve Türkiye'nin Oktak Kültürel Değerleri Uluslar Arası Sempozyumu, 21-23 Mayıs Almatı, 297-312.

Mert, O. (2010). Köl Tigin ve Bilge Kağan Yazıtlarında Yer Alan Ortak Metinlerde Ünsüzleri Karşılayan Karakterlerin Kullanımıyla İlgili Karşılaşılan Farklılıklar. I. Uluslararası Uzak Asya'dan Ön Asya'ya Eski Türkçe Bilgi Şöleni Bildirileri 18-20 Kasım 2009 Afyonkarahisar Türkiye, Afyonkarahisar, 169-190.

Mert, O. (2010). Moğolistan'daki Köktürk Harfli Yazıtlar ve Bugünkü Durumları. Türk Dünyası Mimarlı ve Şehircilik Kurultayı İpek Yolu Medeniyetleri 24-27 Mayıs 2010 Astana / Kazakistan, Bildiriler Kitabı III, 257-268.

Yakar, M. ve Mert, O. (2011). Bursa'daki Türbelerin Fotogrametrik Rölevelerinin Çıkarılması ve Üç Boyutlu Modellemeleri ve Süleyman Çelebi Türbesi Örneği. Kaşgar'dan Endülüs'e Türk - İslam Şehirleri Sempozyumu, Bursa Şehrengizi Bildiriler Kitabı (2830 Nisan 2011), Bursa, 181-184.

Mert, O. (2011). Kars Dokumaları Üzerinde Yer Alan Kültürel ve Epigrafik Ögeler. Uluslararası Kaşgar'dan Endülüs'e Türk-İslam Şehirleri Sempozyumları Gazi Kars Şehrengizi (29-31 Ekim 2011) Bildiler Kitabı, Ankara, 285-302.

Mert, O. (2011). Köl Tigin ve Bilge Kağan Yazıtlarında Yer Alan Ortak Metinlerde Morfolojik Seviyede Karşılaşılan Farklılıklar. Ötüken'den Istanbul'a Türkçenin 1290 Yllı (7202010) From Ötüken to Istanbul, 1290 Years of Turkish (720-2010) 3-5 Aralık, İstanbul / 3th-5th December İstanbul, 433-454.

Mert, O. ve Yakar, M. (2012). Valeh Hacılar’ın “Qıpçaq Çölü” Adlı Şiirinin Kültürel Ögeler Açısından Değerlendirilmesi. Professor Valeh Hacıların Xetiresine Hesr Olunmuş Qafqaz Xalqlarının Folkloru vo Lingvokulturologiyası Mövzusunda Beynelxalq Elmi Simpoziumun Materiallarl, 18-21 Nisan 2012 Tiflis, 336-343.

Mert, O. (2015). Kumanova Müslüman Mezarlığı ve Roman Mezarları. Uluslararası Arap Harfli Yazıtlar Sempozyumu, 19-21 Kasım 2015, Bursa.

Mert, O. ve Bozkırlı, K. (2015) Kutadgu Bilig'deki Eğitsel Ögelerin Modern Eğitim Yaklaşımları Bağlamında Değerlendirilmesi. Cusup Balasagındın 1000 clldıgına arnalgan cıynak, 18-19 Eylül 2015 Bişkek, 11-28. 


\section{- Kitapları ve Kitap Bölümleri:}

Mert, O. (2009). Ötüken Uygur Dönemi Yazıtlarından Tes-Tariat-Şine Us. Ankara.

Mert, O. (2010). Petroglyphs and Tamgas in the vicinity of Gurvan Mandal. Traditional Marking Systems, (Edited by Joám Evans Pim - Sergey A. Yatsenko - Oliver Perrin), London, 349-359.

Mert, O. (2015). Köli Çor Yazıtı ve Anıt Mezar Kompleksi. Erzurum: Atatürk Üniversitesi Yayınları.

3. Prof. Dr. Osman MERT'in Köli Çor Yazıtı ve Anıt Mezar Kompleksi Adlı Eseri: Mert, O. (2015). Köli Çor Yazıtı ve Anıt Mezar Kompleksi. Erzurum: Atatürk Üniversitesi Yayınları. $193 s$.

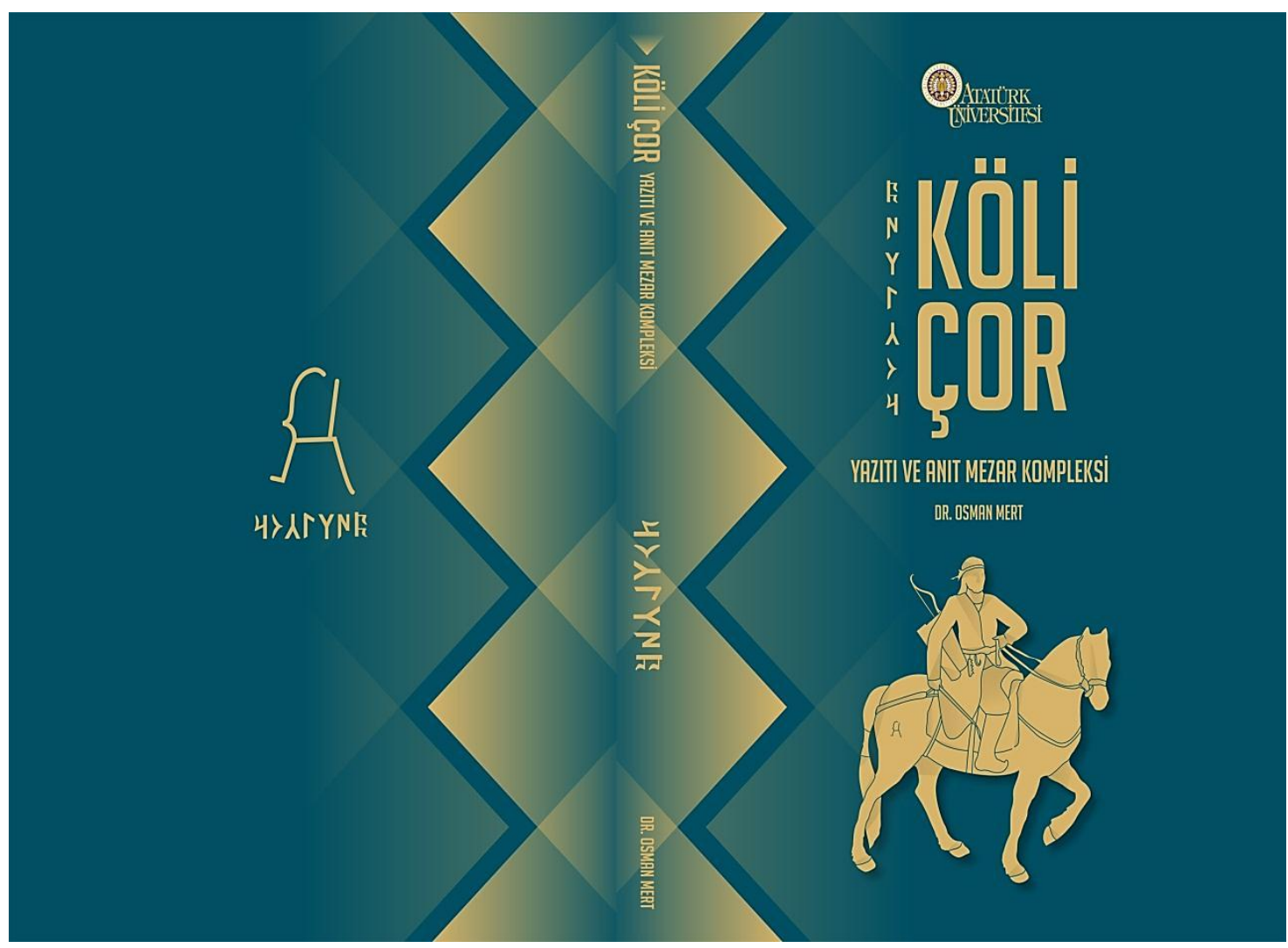

Foto 2: Köli Çor Yazıtı ve Anıt Mezar Kompleksi adlı eserin ön ve arka kapak görüntüleri

Eserin kapak görüntüsünde kullanılan görsel tasarımda sağrısında teke damga bulunan eğerlenmiş at üzerinde savaş hazırlıklarını tamamlayarak harekete geçmiş olan bir Türk savaşçısına yer verilir. Bu tasarım Köli Çor'u tasvir ettiği kadar kuşkusuz ki okuyucuyu da at üzerine bindirip kitap içine aldıktan sonra Orta Asya coğrafyasında dolaştırarak Moğolistan’a götürmeyi de betimler. 
Yazarın annesine ve babasına ithaf ettiği eserinin editörlüğ̈nü eski Türk yazıtları üzerine alanda yapmış olduğu çalışmalarla eski Türk yazıtları üzerine yapılacak çalışmalarda izlenecek yöntem, okuma ve anlamlandırma teklifleri sunma ve bunları bilimsel bir şekilde yayınlama hakkında çığır açmış olan Prof. Dr. Cengiz ALYILMAZ üstlenir.

Köl Tigin ve Bilge Kağan'ın silah arkadaşı Köli Çor adına inşa edilen Köli Çor Anıt Mezar Kompleksi $(60$ x $40 \mathrm{~m}$ ) Moğolistan'ın Töv ile bağlı Delgerhaan ilçesinin Höşööntal bölgesindeki İh Höşööt mevkisinde (48 466659E 5196453N); Orhun Vadisi'nin yaklaşık $60 \mathrm{~km}$ güneyinde; Erdenesant'ın $47 \mathrm{~km}$ güneybatısında bulunmaktadır. Anıt mezar kompleksinin Moğolistan'ın başkenti Ulaanbaatar'a uzaklığı ise 235 km'dir (Mert, 2015, s. 4).

Eserde 149 görsel ögeye (Köli Çor Yazıtı'nın genel ve ayrıntılı görüntülerine, haritalara, Köli Çor Anıt Mezar Kompleksi'ne ve kompleksle ilgili olduğu düşünülen görüntülere) yer verilir.

Eserin I. bölümünde s. 1-36; Köli Çor Yazıtı'nın Adı, Köli Çor Yazıtı'nın Bulunduğu Yer ve Önemi, Köli Çor Yazıtı'nın Ölçüleri, Yazılı Taşa Ait Ölçüler, Yazıtın Kaidesine Ait Ölçüler, Köli Çor Yazıtı'nın Yazım ve Dil Özellikleri, Köli Çor Yazıtı'nda Kullanılan Ünlüler, Köli Çor Yazıtı'nda Kullanılan Ünsüzler, Köli Çor Yazıtı'nda Kullanılan Kalın ve İnce Ünsüzler, Köli Çor Yazıtı'nda Kalın ve İnce Şekilleri, Tek Karakterle Karşılanan Ünsüzler, Köli Çor Yazıtı'nda Kullanılan Çift Ünsüz İşaretleri, Köli Çor Yazıtı'nda Kullanılan Hece İşaretleri, Köli Çor Yazıtı'nda “ø” Boşluk Karakterinin Kullanımı, Köli Çor Yazıtı'nın Söz Varlığı, Köli Çor Yazıtı'nın Söz Varlığının Kavram İşaretleme Metotları Açısından Değerlendirilmesi, Kök veya Köken Hâlindeki Kavram İşaretleri, Gövde Hâlindeki Kavram İşaretleri, Birden Fazla Anlam Ögesiyle Kurulmuş Genel Anlamlı Kalıcı Kavram İşaretleri, Kişi, Boy, Kavim, Millet ve Devlet Adları, Kişi Adları / Unvanlar, Boy, Kavim, Millet ve Devlet Adları ve Coğrafi Adlar konuları ele alınır.

Yazıtın adlandırılması ile ilgili olarak yazıtın bugüne kadar yapılmış olan çalışmalardaki adlandırmalarına yer verilir ve yazıtta geçtiği şeklinin “4>ArYNk / Köli Çor" yazıt için adlandırma olarak tercih edildiği belirtilir (s. 3).

Yazıtın ölçüleri ile ilgili bölümde yazıta ait kaidenin de ayrıntılı ölçülerine değinilir ( $s$. 10). Eserde kullanılan ünlü ve ünsüz harflerin kullanımlarına yazıtta geçtikleri yerler dikkate alınarak örneklerle yer verilerek bu harflerin geçiş adetleri de belirtilir. Ayrıca eserde Köli Çor Yazıtı'ndaki kavram işaretleme yolları da belirlenerek bunlar örnekleri ile birlikte dikkatlere sunulur. 
Eserin II. Bölümünde (s. 37-94) Köli Çor Yazıtı'nın epigrafik belgelemesi ile ilgili bilgiler verilir. Bu bölümde yazıtın batı yüzü, doğu yüzü, güney yüzü, batı yüzünün alt kısmında yatay olarak yer alan satır ve yazıtın kuzey yüzü ele alınır.

Yazıtın batı yüzünün alt kısmında yatay olarak yer alan satır için Mert şunları kaydeder:

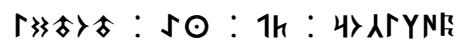

köli çor : (i)t(i)p : (a)nta : țuț̣̂: Köli Çor (halkı) düzenleyip bu zamanda (tebasinl) yönetti (Mert, 2015, s. 90).

Şu ana kadar yapılan yayınların önemli bir kısmında, araştırmacıların yazıtın üzerinde bizzat çalışıp çalışmamalarına bağlı olarak bu satıra ya hiç yer verilmemiş ya da aynı döneme ait yazıtlardaki yazıcıya ait kalıp ifadelerden hareketle bir metin tasarlanmıştır (Mert, 2015, s. 89). ${ }^{2}$

Eserde Mert, epigrafik belgelemeleri dikkatlere sunarken önce yazıtın ilgili yüzünün (Kök)türk harfli metnine yer verir. (Kök)türk harfli metnin belgelemesi yapılırken yazıt üzerinde sağlam olan harfleri siyah; aşınıp dökülen kısımlanı kırmızı; yok olmak üzere olan harfleri mor; okunabilen ancak aşınarak dökülmeye yüz tutmuş harfleri mavi, alttan ve üstten bir kısımları kırılmış harfleri ise yeşil renk ile gösterir. Tamamen dökülmüş / yok olmuş harfler ise eserde “......" ile dikkatlere sunulur. Ardından (Kök)türk harfli belgelemeden sonra yazı çevirimi yapılır; bu yazı çeviriminin Türkiye Türkçesine aktarımına ait bilgiler sıralanır. Bu belgeleme yapılırken (Kök)türk harfli metin, yazı çevirimi metni ve Türkiye Türkçesine aktarımında Köli Çor Yazıtı üzerine daha önce yapılmış okuma ve anlamlandırma çalışmaları dikkate alınarak farklılıklar dipnotlarla ayrıntılı bir şekilde gösterilir.

III. Bölümde (s. 95-144) Köli Çor Yazıtı Anıt Mezar Kompleksi içinde bulunan yapılar fiziki özellikleriyle birlikte ayrıntılı olarak ele alınır. Bu doğrultuda başlangıçta eski Türk mezar geleneği hakkında bilgiler verilir. Ardından anıt mezar kompleksinin mimari planına yer verilerek anıt mezar kompleksindeki barkın ve sunak masasının bugünkü durumu ele alınır. Anıt mezar kompleksinde yer alan 8 insan heykelinin önden ve yandan çekilmiş ayrıntılı görüntüleri ile bunların ölçüleriyle birlikte çizimlerine; koç, koyun ve aslan heykellerinin görüntülerine, çizimlerine ve yapım özelliklerine yer verilir.

\footnotetext{
${ }^{2}$ Ayrıntılı bilgi için $b k$. Mert, 2015, s. 90.
} 
Köli Çor Anıt Mezar Kompleksi'nde yer alan heykellerin diğer anıt mezar komplekslerindekilerle karşılaştıııldıklarında aynı ustalıkta yapılmadıkları; bire bir insan boyutunda olmadıkları; daha küçük tasarlandıkları görülür (Mert, 2015, s. 124).

Bölümün sonunda Köli Çor'un savaş̧̧1lı̆̆ını betimleyen; öldürdüğü her düşman için dikilerek oluşturulan balbal dizisi hakkındaki bilgilerle görüntüler bulunur:

Köli Çor Anıt Mezar Kompleksi'nde yazıtın bulunduğu bölgeden doğuya doğru 1800 m boyunca devam eden 189 balbal bulunmaktadır. Bu balballardan son 9 tanesi kuzeye doğru kavis çizer şekilde dikilmişlerdir (Mert, 2015, s. 141).

Eserde IV. Bölümde (s. 145-156) Köli Çor Yazıtı'nın söz varlığı ele alınarak oluşturulan bir sözlük - dizin bulunur. Sözlük ve dizin oluşturulurken önce kavram işaretinin yazı çevirimi, ardından Türkiye Türkçesindeki anlamı dikkatlere sunulup kavram işaretlerinin karşılarında ise (Kök)türk harfleriyle yazıtta geçtiği şekline, yazı çevirimine ve yazıtta geçtiği yere dair bilgilere yer verilir:

arțuk: fazla, çok

bengi: ebedî

çoḷugan: k. a.

el: devlet, halk, ülke

kerü: arka, bat1

ögüz: 1rmak

süngüş: savaş

toḳuz: dokuz, sayı adı

ẏag̀ı: düşman

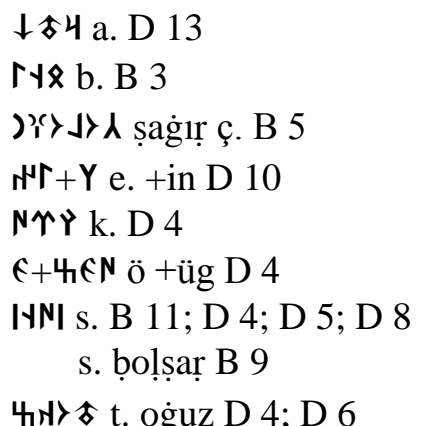

SN+ז’́ ẏ. +ḳa D 11 (Mert, 2015)

Eserin V. Bölümünde (s. 157 - 188) Köli Çor Yazıtı, eski Türk yazıtları, Türk tarihi, medeniyeti, coğrafyası, sanatı $v b$. hakkında eserin hazırlanmasında kullanılan kaynakların oluşturduğu geniş bir bibliyografya ve eserin sonunda da ek olarak Prof. Dr. Osman MERT'in öz geçmişi $(s .189$ - 192) bulunur.

Eski Türk yazıtları ile ilgili yapılmış çalışmalar arasında kendisine önemli bir yer bulacağına inandığımız bu eserinden dolayı Prof. Dr. Osman MERT’e teşekkür eder; (Kök)türk harfli yazıtlarla ilgili diğer çalışmalarının sabırsızlıkla beklendiğini burada dile getirmek isterim. 